Nada Nashee Al-Hafidh

BDS, MSc. (Asst. Lec.)

Afrah Khazal Al Hamdany BDS, MSc. PhD. (Asst. Prof.)

Lamiaa Abdulrhman Hasan BDS, MSc. (Asst. Lec.)

\section{Speeding Orthodontics: A Review Article}

Depart. of Pedodontic, Ortho. and Preventive Dentistry

College of Dentistry, University of Mosul

Depart. of Pedodontic, Ortho. and Preventive Dentistry

College of Dentistry, University of Mosul

Depart. of Pedodontic, Ortho. and Preventive Dentistry

College of Dentistry, University of Mosul

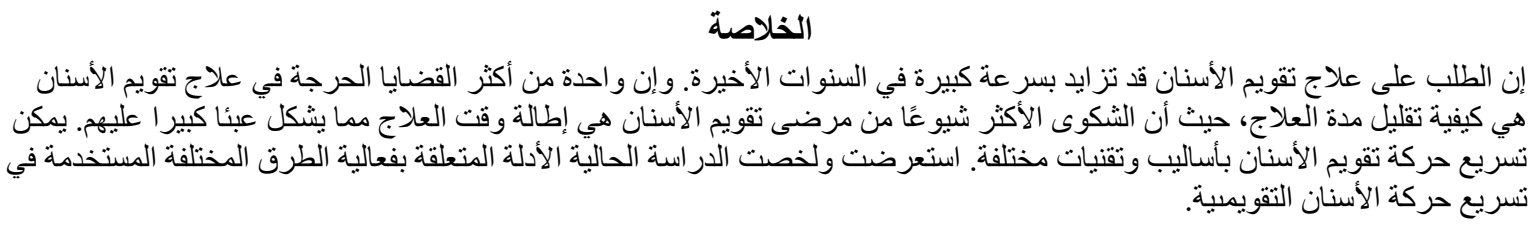

\begin{abstract}
The request for orthodontic treatment has grown quickly in the last years. One of the most critical issues in orthodontic treatment is how to decrease the duration of orthodontic treatment since the most common complaint of orthodontic patients is prolong the time of treatment which is a huge burden on patients. Orthodontic tooth movement can be enhanced by different methods and techniques. The current study reviewed and summarized the evidence regarding the success of different methods on speeding orthodontic tooth movement.
\end{abstract}

Keywords: Acceleration, Orthodontics, Speeding, Tooth movement.

Al-Hafidh NN., Al Hamdany A kh., Hasan LA. Speeding Orthodontics: A Review Article. AL-Rafidain Dent J. 2021; 21(2):177-184.

DOI: 10.33899/rdenj.2021.128952.1067 @2020, College of Dentistry, University of Mosul.

Received: 20/10/2020 Sent to Referees: 25/10/2020

This is an open access article under the CC BY 4.0 license
Accepted for Publication: 14/1/2021 (http://creativecommons.org/licenses/by/4.0/).

\section{INTRODUCTION}

Extended orthodontic treatment could upsurge numerous problems including caries, root resorption, and periodontal diseases ${ }^{(1)}$. The mean duration of comprehensive orthodontic treatment is around two years with a difference that can be exaggerated by various factors ${ }^{(1,2)}$.
Decreasing this average time became increasingly important to both orthodontists and patients. The speed of orthodontic tooth movement (OTM) is depending on the remodeling of bone around the apices of the teeth ${ }^{(3)}$. Remodeling of the bone is regimented mechanisms of cellular behavior regulation, for that reason, 
OTM can be accelerated by determining and directing the cellular regulators. The biological response of tissues toward orthodontic forces determines teeth movement ${ }^{(3)}$. Acceleration of OTM can be done by different methods and techniques, including: chemical stimulation, physical stimulation and surgical aided procedures.

So, this review aims to summarize the evidence concerning the efficiency of different methods on accelerating OTM.

\section{Chemical stimulation.}

There are various chemical agents are used to accelerate OTM such as corticosteroid, cytotoxins, Vitamin D, leukotrienes and vasoactive medications. However, these medications have systemic effects rather than local effects on targeted cells ${ }^{(4-7)}$. A few studies showed that Local administration of vitamin D3 appeared to increase the rate of OTM $^{(4,6,7)}$.

\section{Physical stimulation}

This method involves mechanical and physical stimulation of periodontal ligaments such as application of the electromagnetic field, a low dose of laser and vibration applications. There is a weak evidence support the application of pulsed electromagnetic field electromagnetic to accelerate OTM ${ }^{(8,9)}$. Low-level laser therapy (LLLT) has been used to hasten OTM in recent years ${ }^{(10,11)}$. Colson et al., 2017 stated that LLLT can be effective for speeding $\mathrm{OTM}^{(10)}$. However, further investigation is required to focus on finding the optimal wave- length and dose for LLLT. High-quality studies are obligatory to determine the effects of LLLT and its optimal protocols for speeding OTM ${ }^{(10)}$. LLLT can be also used during the retention period to reduce relapse tendency because it may induce bone formation ${ }^{(12)}$.

Vibrations are also used as a method of acceleration of OTM. Vibration consists of High-frequency oscillatory forces of low magnitude has shown osteogenic and anti-catabolic effects on bone ${ }^{(13)}$. Conflicting results about the effect of vibration on acceleration of OTM are shown in studies (13-16). AcceleDent Optima (OrthoAccel Technologies, Inc., Bellaire, TX) is a cleared device that generates vibration forces to the teeth and it is claimed to accelerate OTM ${ }^{(16)}$. Although many researches were conducted to study the effect of vibration on the acceleration of OTM, weak evidence specifies that vibration is active for accelerating canine retraction ${ }^{(16)}$.

\section{Surgical aided procedures}

The concept behind these surgical procedures is to initiate injury within the bone which in turn enhance the biological response of tissues, acceleration of OTM is achieved by physiological recovery mechanism, this mechanism includes firstly osteoclastic activities and then rapid osteoblastic activity decreases the resistance of the bone ${ }^{(17)}$. The tissue response to these changes is called a regional acceleratory phenomenon (RAP) ${ }^{(17)}$, which is consisted of temporary localized demineralization of bone 
and intensified bone turnover in injured regions.

\subsection{Corticotomy-assisted treatments}

Surgical procedures to shorten orthodontic treatment have been practiced since the fifties when Köle introduced the one-block technique $^{(18)}$. This technique has been used to allow the movement of bone blocks. It involves the creation of a full-thickness flap and removal of buccal and lingual interdental cortical bone and alveolar bone below the roots of the teeth to combine these cuts into one block. Köle claimed that periodontal damage and pulpal mortality can be prevented when bone marrow is kept intact. In 1991 Suya replaced Köle's method with supra-apical horizontal corticotomies beyond the apices of the teeth ${ }^{(19)}$. Suya claimed that his method was less painful, producing less root resorption, and exhibiting less relapse despite the minimal gingival recession. The original technique was changed in 1998 by Liou and Huang ${ }^{(20)}$. They used perforations on the bone instead of cuts. This procedure made the surgery simple and effective.

\subsection{Periodontal ligament distraction}

This technique was done by a distraction device which placed on canine and molar following extraction of first premolar ${ }^{(20)}$. Canine moved into the space of extracted first premolar. The surgical preparation includes using bur to undermine the inter-septal bone distal to the canine and make buccal and lingual vertical groove inside the extraction socket toward its end ${ }^{(20) .}$ The distraction device was activated by
0.5 to $1.0 \mathrm{~mm} /$ day immediately after placement. The canine retraction was completed in 3 weeks with slight anchorage loss. However, the disadvantage of this method is a sensitive surgical procedure ${ }^{(21)}$.

\subsection{Dentoalveolar distraction}

In 2002, Kişnişci et al. (22) introduced dentoalveolar distraction. In this method, a rigid distraction device was applied before premolar teeth extraction and the osteotomy cut curved apically from the apex of the canine. The buccal cortical bone of the socket was carefully removed after extraction. The distraction device was inserted immediately with 0.4 $\mathrm{mm}$ activation twice daily. The canine distraction was completed with approximately less than 2 weeks without significant anchorage loss. The adverse effects of dentoalveolar distraction such as root resorption or loss of vitality were not reported ${ }^{(22)}$. However, more good quality studies are recommended to support this finding ${ }^{(23)}$. Although a faster rate of canine retraction is accomplished compared to periodontal ligament distraction, however, it is a more invasive technique ${ }^{(22)}$.

\subsection{Periodontally accelerated osteogenic orthodontics}

In 2001, Thomas and William Wilcko ${ }^{(24)}$ introduced a new technique called Accelerated Osteogenic Orthodontics. They claimed that decortication of bone over roots after corticotomy enhances the response to orthodontic forces. This response can be explained according to the RAP process. They combined surgical 
preparation with alveolar augmentation, therefore, they did not rely on original alveolar volume. The approach included a full-thickness flap, decortication of bone and alveolar augmentation. The bone graft is intended to prevent bone height loss, periodontal damage and inducing bone formation. They claimed that faster OTM and less resorption was achieved in this method. Wilcko and Wilcko used resorbable bone graft to prevent fenestration of bone (25). The disadvantages of this method include post-operative pain and low acceptance by patients ${ }^{(25)}$.

\subsection{Corticision}

Corticision is a flapless minimally invasive technique was introduced by Park et al. ${ }^{(26)}$ as alternative for corticotomy procedures. The researchers used a scalpel and surgical chisel on the attached gingiva inter-radicular and to make an incision in interproximal cortical bone at 45-60 angle of with the long axis of root without raising a full flap ${ }^{(26)}$. Incisions were 10 $\mathrm{mm}$ in depth. Park reported that orthodontic treatment was finalized in 10 months through this method. However, there is a study done on rats revealed that corticision does not increase bone matrix remodeling ${ }^{(27)}$.

\subsection{Piezocision}

It is a minimally invasive technique introduced by Dibart et al. in $2009^{(28)}$. This procedure includes a flapless localized piezoelectric alveolar decortication. The biological bases of this method are based on RAP ${ }^{(17)}$. The vibrations of the piezosurgery device are also claimed to contribute to a faster movement ${ }^{(29)}$. However, these vibrations cause discomfort in some patients. This method requires an expensive device, a piezotome, and all clinics cannot have this device available ${ }^{(30)}$. Piezocision is considered a more conservative procedure compared with corticotomy because it protects the periodontium (31). However, the disadvantage of this method is residual scars which may affect might aesthetic in certain cases such as high smile line ${ }^{(30)}$.

Abbas et al., 2016 reported significant difference between piezocision and corticotomy-facilitated orthodontics in term of rate of canine movement ${ }^{(32)}$. The piezocision procedure allows the addition of biomaterials in cases of deficiency in the alveolar bone ${ }^{(33)}$. However, recent meta-analysis reported that quality of evidence is low regarding the efficiency of piezocision in acceleration of OTM ${ }^{(29,34)}$.

\subsection{Discision method}

Discision introduced in 2018 to accelerate OTM in patients with crowding in maxillary and mandibular arches ${ }^{(35)}$. This method can effectively hasten OTM by $35.5 \%{ }^{(36)}$. Discision involves the use a disc-shaped saw-bur inserted on a micromotor which is usually used for implant surgery. This disc is thinner than piezosurgery knife by $0.3 \mathrm{~mm}$ and it is available with less cost than piezosurgery devices ${ }^{(36)}$. Therefore; it provides a cheaper substitute for piezocision with less possibility of damage to the adjacent roots ${ }^{(36)}$. Disc saws create incision with $3 \mathrm{~mm}$ in depth and $5-8 \mathrm{~mm}$ in length. The 
body of bur act as a stopper therefore, a controlled incision line can be obtained way than in the piezocision method (35,36). The authors claimed that no scar tissue or root resorption was detected ${ }^{(36)}$.

\subsection{Micro-osteoperforations (MOP)}

Another less invasive an alternative maneuver is perforations in the buccal cortical bone ${ }^{(37)}$. Teixeira et al. 2010 created holes of about $0.25 \mathrm{~mm}$ in depth and $0.25 \mathrm{~mm}$ in diameter and investigated cytokine expression and tooth movement in adult rats ${ }^{(38)}$. They also discovered that micro-osteoperforations (MOP) significantly increased the rate of OTM in the intervention group. Teixeira et al concluded that these perforations can accelerate bone remodeling ${ }^{(38)}$. Moreover, a recent meta-analysis revealed that there is a statistically significant rate of canine retraction but not a clinically substantial effect ${ }^{(39)}$. In addition to that, other study revealed that a double the number of perforations results in significant acceleration of canine retraction $^{(40)}$. For further note, there is a study observed that MOP does not affect root resorption ${ }^{(41)}$. On the other hand, there are different meta-analyses that did not support the claim that MOP could accelerate OTM significantly ${ }^{(42,43)}$.

\section{REFERENCES}

1. Zahrowski J, Jeske A. Apical root resorption is associated with comprehensive orthodontic treatment but not clearly dependent on prior tooth characteristics or orthodontic techniques. J Am Dent Assoc. 2011; 142(1):66-68.

2. Talic N F. Adverse effects of orthodontic treatment: A clinical perspective. Saudi Dent J. 2011; 23(2):55-59.

3. Huang H, Williams RC, Kyrkanides S. Accelerated orthodontic tooth movement: Molecular mechanisms. Am J Orthod Dentofacial Orthop. 2014; 146(5):620632.

4. Al-sayagh N, Al-Jumaili Kh, AI-Sadi H. Effect of local injection of 1,25- dihydroxycholecalciferol on the velocity of Orthodontic Tooth Movement and Bone Density. Int. J. Enh. Res. Sci. Tec. Eng.2014; 3(4)146-155.

5. Teixeira CC, Khoo E, Tran J, et al. Cytokine expression and accelerated tooth movement. J Dent Res. 2010; 89(10):1135-1141 .

6. Iosub Ciur MD, Zetu IN, Haba D, Viennot S, Bourgeois D, Andrian S. Evaluation of the Influence of Local Administration of Vitamin D on the Rate of Orthodontic Tooth Movement. Rev Med Chir Soc Med Nat Iasi. 2016; 120(3):694-699.

7. Varughese ST, Shamanna PU, Goyal N, et al. Effect of Vitamin D on Canine Distalization and Alveolar Bone Density Using Multi-slice Spiral CT: A Randomized Controlled Trial. J Contemp Dent Pract. 2019; 20(12):1430-1435. 
8. Yi J, Xiao J, Li H, Li Y, Li X, Zhao Z. Effectiveness of adjunctive interventions for accelerating orthodontic tooth movement: a systematic review of systematic reviews. J Oral Rehabil. 2017; 44(8):636654.

9. Long H, Pyakurel U, Wang Y, Liao L, Zhou Y, Lai W. Interventions for accelerating orthodontic tooth movement: a systematic review. Angle Orthod. 2013; 83(1):164-171.

10. Fromont-Colson, C., Marquez-Diaz, M., Badran, Z. et al. Efficiency of low-level laser therapy for orthodontic tooth movement: a review. Laser Dent Sci. 2017;1:47-56.

11. Baghizadeh Fini M, Olyaee P, Homayouni A. The Effect of Low-Level Laser Therapy on the Acceleration of Orthodontic Tooth Movement. J Lasers Med Sci. 2020; 11(2):204-211.

12. Franzen TJ, Zahra SE, El-Kadi A, Vandevska-Radunovic V. The influence of low-level laser on orthodontic relapse in rats. Eur J Orthod. 2015; 37(1):111117.

13. Al-sayagh N, Al-Jumaili Kh. The Effect of Mechanical Vibration on the velocity of Orthodontic tooth Movement Effect of mechanical vibration on orthodontic tooth movement. Int. J. Enh. Res. Sci. Tec. Eng. 2014; 3(1): 284-291.

14. Uribe F, Dutra E, Chandhoke T. Effect of cyclical forces on orthodontic tooth movement, from animals to humans. Orthod Craniofac Res. 2017; 20(Suppl 1):68-71.

15. Aljabaa A, Almoammar K, Aldrees A, Huang G. Effects of vibrational devices on orthodontic tooth movement: A systematic review. Am J Orthod Dentofacial Orthop. 2018; 154(6):768-779.

16. Jing D, Xiao J, Li X, Li Y, Zhao Z. The effectiveness of vibrational stimulus to accelerate orthodontic tooth movement: a systematic review. BMC Oral Health. 2017;17(1):143.

17. Frost HM. The regional acceleratory phenomenon: A review. Henry Ford Hosp Med J. 1983; 31(1):3-9.

18. Köle H. Surgical operations on the alveolar ridge to correct occlusal abnormalities. Oral Surg Oral Med Oral Pathol. 1959; 12(5):515-529.

19. Suya H. Corticotomy in orthodontics. In: Hosl E, Baldauf A, editors. Mechanical and Biological Basis in Orthodontic Therapy. Heidelberg, Germany: Huthig Buch Verlag;1991. Pp. 207-226.

20. Liou EJ, Huang CS. Rapid canine retraction through distraction of the periodontal ligament. Am J Orthod Dentofacial Orthop. 1998; 114(4):372-382.

21. Kumar PS, Saxena R, Patil S, Keluskar KM, Nagaraj K, Kotrashetti SM. Clinical investigation of periodontal ligament distraction osteogenesis for rapid orthodon- 
tic canine retraction. Aust Orthod J. 2009; 25(2):147-152.

22. Kişnişci RS, Işeri H, Tüz HH, Altug AT. Dentoalveolar distraction osteogenesis for rapid orthodontic canine retraction. $\mathbf{J}$ Oral Maxillofac Surg. 2002; 60(4):389394.

23. Yadav S, Markiewicz MR, Allareddy V. Dentoalveolar Distraction Osteogenesis for Rapid Maxillary Canine Retraction: An Overview of Technique, Treatment, and Outcomes. Oral Maxillofac Surg Clin North Am. 2020; 32(1):83-88.

24. Wilcko WM, Wilcko T, Bouquot JE, Ferguson DJ. Rapid orthodontics with alveolar reshaping: Two case reports of decrowding. Int J Periodontics Restorative Dent. 2001; 21(1):9-19.

25. Wilcko MT, Wilcko WM, Pulver JJ, Bissada NF, Bouquot JE. Accelerated osteogenic orthodontics technique: a 1-stage surgically facilitated rapid orthodontic technique with alveolar augmentation. J Oral Maxillofac Surg. 2009; 67(10):2149-2159.

26. Park YG. Corticision: A Flapless Procedure to Accelerate Tooth Movement. Front Oral Biol. 2016; 18:109-117.

27. Peron AP, Johann AC, Papalexiou V, et al. Tissue responses resulting from tooth movement surgically assisted by corticotomy and corticision in rats. Angle Orthod. 2017; 87(1):118-124.
28. Dibart S. Piezocision ${ }^{\mathrm{TM}}$ : Accelerating Orthodontic Tooth Movement While Correcting Hard and Soft Tissue Deficiencies. Front Oral Biol. 2016; 18:102108.

29. Figueiredo DS, Houara RG, Pinto LM, et al. Effects of piezocision in orthodontic tooth movement: A systematic review of comparative studies. J Clin Exp Dent. 2019; 11(11):e1078-e1092.

30. Charavet C, Lecloux G, Bruwier A, et al. Localized Piezoelectric Alveolar Decortication for Orthodontic Treatment in Adults: A Randomized Controlled Trial. J Dent Res. 2016; 95(9):1003-1009.

31. Viwattanatipa N, Charnchairerk S. The effectiveness of corticotomy and piezocision on canine retraction: A systematic review. Korean J Orthod. 2018; 48(3):200-211.

32. Abbas NH, Sabet NE, Hassan IT. Evaluation of corticotomy-facilitated orthodontics and piezocision in rapid canine retraction. Am J Orthod Dentofacial Orthop. 2016; 149(4):473-480.

33. Charavet C, Lambert F, Lecloux G, Le Gall M. Traitement orthodontique accéléré par corticotomies: quelles sont les alternatives minimalement invasives? [Accelerated orthodontic treatment using corticotomies: what are the minimally invasive alternatives?]. Orthod Fr. 2019; 90(1):5-12. 
34. Figueiredo DS, Houara RG, Pinto LM, et al. Effects of piezocision in orthodontic tooth movement: A systematic review of comparative studies. J Clinical and Experimental Dentistry. 2019; 11(11):e1078-e1092.

35. Buyuk SK, Yavuz MC, Genc E, Sunar O. A novel method to accelerate orthodontic tooth movement. Saudi Med J. 2018; 39(2):203-208.

36. Yavuz MC, Sunar O, Buyuk SK, Kantarc1 A. Comparison of piezocision and discision methods in orthodontic treatment. Prog Orthod. 2018; 19(1):44.

37. Alfawal AMH, Hajeer MY, Ajaj MA, Hamadah O, Brad B. Evaluation of piezocision and laser-assisted flapless corticotomy in the acceleration of canine retraction: a randomized controlled trial. Head Face Med. 2018; 14(1):4

38. Teixeira CC, Khoo E, Tran J, et al. Cytokine expression and accelerated tooth movement. J Dent Res. 2010; 89(10):1135-1141.

39. Shahabee M, Shafaee H, Abtahi M, Rangrazi A, Bardideh E. Effect of microosteoperforation on the rate of orthodontic tooth movement-a systematic review and a meta-analysis. Eur J Orthod. 2020; 42(2):211-221.
40. Babanouri N, Ajami S, Salehi P. Effect of mini-screw-facilitated microosteoperforation on the rate of orthodontic tooth movement: a single-center, splitmouth, randomized, controlled trial. Prog Orthod. 2020; 21(1):7.

41. Aboalnaga AA, Salah Fayed MM, ElAshmawi NA, Soliman SA. Effect of micro-osteoperforation on the rate of canine retraction: a split-mouth randomized controlled trial. Prog Orthod. 2019; 20(1):21.

42. Fu T, Liu S, Zhao H, Cao M, Zhang R. Effectiveness and Safety of Minimally Invasive Orthodontic Tooth Movement Acceleration: A Systematic Review and Meta-analysis. J Dent Res. 2019; 98(13):1469-1479.

43. Alkebsi A, Al-Maaitah E, Al-Shorman H, Abu Alhaija E. Three-dimensional assessment of the effect of microosteoperforations on the rate of tooth movement during canine retraction in adults with Class II malocclusion: A randomized controlled clinical trial. Am J Orthod Dentofacial Orthop. 2018; 153(6):771-785. 